\title{
Genetic determinants of hair and eye colours in the Scottish and Danish populations
}

\author{
Jonas Mengel-From $^{\dagger 1}$, Terence H Wong ${ }^{\dagger 2,3}$, Niels Morling1, Jonathan L Rees ${ }^{2}$ \\ and Ian J Jackson*3
}

Address: ${ }^{1}$ Section of Forensic Genetics, Department of Forensic Medicine, Faculty of Health Sciences, University of Copenhagen, Denmark, ${ }^{2}$ Department of Dermatology, University of Edinburgh, 1/F, Lauriston Building, Lauriston Place, Edinburgh, EH3 9HA, UK and ${ }^{3}$ MRC Human Genetics Unit, Institute of Genetics and Molecular Medicine, Western General Hospital, Edinburgh, EH4 2XU, UK

Email: Jonas Mengel-From - jmengel76@hotmail.com; Terence H Wong - T.Wong@ed.ac.uk; Niels Morling - Niels.Morling@forensic.ku.dk; Jonathan L Rees - jonathan.rees@ed.ac.uk; Ian J Jackson* - ian.jackson@hgu.mrc.ac.uk

* Corresponding author †Equal contributors

Published: 30 December 2009

BMC Genetics 2009, 10:88 doi:10.1/86/147|-2156-10-88
Received: 18 June 2009

Accepted: 30 December 2009

This article is available from: http://www.biomedcentral.com//47/-2/56/10/88

(c) 2009 Mengel-From et al; licensee BioMed Central Ltd.

This is an Open Access article distributed under the terms of the Creative Commons Attribution License (http://creativecommons.org/licenses/by/2.0), which permits unrestricted use, distribution, and reproduction in any medium, provided the original work is properly cited.

\begin{abstract}
Background: Eye and hair colour is highly variable in the European population, and is largely genetically determined. Both linkage and association studies have previously been used to identify candidate genes underlying this variation. Many of the genes found were previously known as underlying mutant mouse phenotypes or human genetic disease, but others, previously unsuspected as pigmentation genes, have also been discovered.
\end{abstract}

Results: We assayed the hair of a population of individuals of Scottish origin using tristimulus colorimetry, in order to produce a quantitative measure of hair colour. Cluster analysis of this data defined two groups, with overlapping borders, which corresponded to visually assessed dark versus red/light hair colour. The Danish population was assigned into categorical hair colour groups. Both cohorts were also assessed for eye colour. DNA from the Scottish group was genotyped at SNPs in 33 candidate genes, using 384 SNPs identified by HapMap as representatives of each gene. Associations found between SNPs and colorimetric hair data and eye colour categories were replicated in a cohort of the Danish population. The Danish population was also genotyped with SNPs in 4 previously described pigmentation genes. We found replicable associations of hair colour with the KITLG and OCA2 genes. MCIR variation correlated, as expected, with the red dimension of colorimetric hair colour in Scots. The Danish analysis excluded those with red hair, and no associations were found with $M C I R$ in this group, emphasising that $M C I R$ regulates the colour rather than the intensity of pigmentation. A previously unreported association with the HPS 3 gene was seen in the Scottish population. However, although this replicated in the smaller cohort of the Danish population, no association was seen when the whole study population was analysed.

Conclusions: We have found novel associations with SNPs in known pigmentation genes and colorimetrically assessed hair colour in a Scottish and a Danish population.

\section{Background}

The colours of hair, skin and eyes provide some of the most visible variation between and within human popu- lations. Whilst variation in skin pigmentation is notable between populations, hair colour variation is most notable within populations of European origin [1,2]. In Euro- 
peans, genetic factors explain $92 \%$ of the variation in hair colour, while most of the rest of the variation is due to environmental influence [2]. Blond and red hair colours are commonly seen variations in Europeans, but are rare in other populations. Both linkage studies in families and genome-wide association studies in populations have identified genetic factors that determine hair and eye colour. Thus, for example, brown eye and hair colour was mapped to chromosome 15 by linkage $[3,4]$ and was also found associated with SNPs in the OCA2, and adjacent HERC2 genes in both whole genome and candidate studies [4][5][6][7][8]. Red hair colour was initially attributed to $M C 1 R$ variation by association studies [9] but the highly penetrant phenotype of some variants subsequently allowed family studies [10]. Presently, more than 70 variations in $M C 1 R$ have been reported [11]. The commonest variants in $M C 1 R$ have been characterised as highly penetrant or low penetrant red hair alleles and classified as $R$ or $r$, respectively [12]. Red-haired individuals most commonly are $R / R$ genotype, and this genotype accounts for as much as $84 \%$ of red hair colour, but $R / r$, $R /+$ and $r / r$ genotypes can also result in red hair [12][13][14]. Association analyses between hair colour and SNPs in Europeans have been more informative than linkage analyses and have revealed associations with several genes, most already known from mouse or human pigmentary mutations; SLC45A2, TYR, OCA2, KITLG, ASIP, and TYRP1 but others not previously implicated in pigmentation; SLC24A4, IRF4 and TPCN2 $[4,5,15,16][17]$. In addition, recently four groups have independently found strong associations between eye colour and polymorphisms in the HERC2 gene upstream of OCA2 [5][6][7][8]. These SNPs also have a weak association with hair colour, but there are notably stronger associations with hair colour and haplotypes across the OCA2 gene itself [4].

The precise mechanisms behind most SNP associations with hair colour are not clear. However, most associations found using whole-genome studies map in or near to genes which are already known to play a role in pigmentation through human, mouse or zebrafish mutations. It is clear that most components of the pigmentation path- way are already known through mutation and disease studies and that subtle changes in expression or function of these genes underlie much of normal pigmentary variation.

On this principle, we have studied associations between 384 tagging SNPs which comprehensively cover 33 candidate genes known to be involved in the pigmentation pathway from mouse and human disease genetics or other studies and hair and eye colour in a Scottish population. Associations with hair colour were followed up in a Danish population using 25 SNPs in regions of four candidate pigmentation genes and hair colour.

\section{Methods}

\section{The Scottish population}

A total of 133 unselected young adults of ages ranging from 18 to 40 (32 males and 101 females) were recruited from Edinburgh, Scotland. Their hair colour was measured from 6 scalp hair sites: left and right frontal $(8 \mathrm{~cm}$ superiorly from supraorbital ridge), left and right temple ( $8 \mathrm{~cm}$ laterally from supraorbital ridge), left and right occipital (5 cm laterally from occiput) using tristimulus $\mathrm{L}^{*} \mathrm{a}^{*} \mathrm{~b}^{*}$ colorimetry with a Minolta spectrophotometer CM-2600d (Minolta Co., Ltd, Osaka, Japan). Means of triplicate measurements over all sites were taken. Colour was represented as summary values in three dimensions designed to be commensurable with human colour perception: $\mathrm{L}^{*}$, representing lightness, on a scale of $0-100$ where 0 is black and 100 is white; $a^{*}$, representing redgreen, on a scale from +60 to -60 , where positive values indicate increasing shades of red; and $\mathrm{b}^{*}$, representing a yellow-blue, on a scale from +60 to -60 , with positive values representing increasing shades of yellow. These three values were plotted and intersected into a three dimensional space to give a numerical value for colour. Subjects with dyed hair and/or who were not of north-European origin were excluded from the study. The eyes of the participants were photographed and categorized into blue, grey, green hazel or brown by inspection. Table 1 shows the numbers of subjects by eye colour, pooled to give sufficient statistical power, with their hair colour by observation. From all volunteers, venous blood was collected and

Table I: Eye and hair colour of I33 Scots in this study

\begin{tabular}{lccccc}
\hline & Black hair & Brown hair & Fair hair & Red hair & Totals \\
\hline Blue/grey eyes & 3 & 19 & 21 & 7 & 50 \\
\hline Brown/hazel eyes & 18 & 31 & 2 & 7 & 58 \\
\hline Green eyes & 2 & 13 & 4 & 25 & 20 \\
\hline Totals & 23 & 63 & 27 & 133 \\
\hline
\end{tabular}


DNA was extracted using Nucleon Genomic DNA extraction kit (Tepnel Life Sciences PLC, Manchester, UK). Ethical approval was obtained from the Lothian Regional Ethics Committee, and consent to carry out and publish the study obtained from each subject.

\section{The Danish population}

Unrelated, healthy donors participated and their hair colours categorised as white, light blond, dark blond, brown, black, red or auburn by the same observer. Elderly participants answered by recall of their colour at age 20 years. Data and genotypes from 378 participants with hair colour other than red were analysed with respect to dark or blond hair colour and were tested at 25 SNPs. Initial validation of SNP associations with hair colour in the Scottish population used a subset of participants from the Danish cohort $(\mathrm{N}=210)$ with subsequent follow up in the whole sample. The hair colours were classified as dark (dark blond, brown, black) or light (fair, light blond). Table 2 shows the hair and eye colour categories from this population. Participants were asked where their parents or grandparents were born to determine the individual's ancestral origin, and only those of north European ancestry were included. Blood samples were collected from all volunteers and DNA was purified using the QIAamp DNA blood minikit according to the manufacturer protocol (Qiagen). The project was approved by the Danish ethical committee (ref. KF-01-037/03), and consent to carry out and publish the study obtained from each subject.

In this population the sample size of 210 achieves $67 \%$ power to detect at $\mathrm{P}=0.05$ an association with an odds ratio of 1.6 for a SNP with a minor allele frequency of 0.45 (as we see, for example with rs2254913 in HPS3)

\section{Candidate genes and SNP selection}

A total of 33 candidate genes were selected which are reported to play a role in pigmentation through melanin biosynthesis, metabolic pathways associated with pigmentation or tanning response or melanocyte biology. The candidate genes were: ASIP, BLOC1S3, CYP1A2, CYP2C8, CYP4B1, DCT, DTNBP1，ERCC1， ERCC2, ERCC3, ERCC4, ERCC5, ERCC6, ERCC8, GNAS, GPR143,
HPS1, HPS3, HPS4, HPS5, HPS6, KIT, KITLG, MITF, MYO5A, OCA2, PRKAR1A, SLC24A5, SLC45A2, SOX10, TP53, TYR and TYRP1. SNPs from these and other genes were screened using data from CEU in HapMap, viewed in Haploview, http://www.hapmap.org. Tagging SNPs were selected as representatives of the candidate gene as an alternative to analyzing all known SNPs in the candidate genes and to minimize the chance of analysis SNPs in strong linkage disequilibrium with each other.

The choice of SNPs was refined by looking at frequency in the European population and suitability for analysis on the Illumina platform. The Illumina Assay Design Tool was used to refine and eliminate cross hybridisation and improve success rate. SNP selection used design score, design rank, minor allele frequency (MAF) and validation status. MAF, Golden Gate validation status and SNP scores were obtained from Illumina.

\section{SNP typing with Illumina microarray (Scots)}

The Illumina GoldenGate microarray system was used for genotyping of the Scottish samples [18]. Typing was performed at the Wellcome Trust Clinical Research Facility, Institute of Genetics and Molecular Medicine, Edinburgh [19].

\section{SNP typing by MALDI-TOF MS (Danes)}

A multiplex PCR with 13 short amplicons was designed to amplify the loci with the selected 13 candidate variations [see Additional file 1, Table S1]. Primer concentrations ranging from $26.7 \mu \mathrm{M}$ to $66.7 \mu \mathrm{M}$ [see Additional file 1, Table S2]. The reaction was balanced to obtain equal peak intensities in the MALDI-TOF MS spectra. PCRs and detection by MALDI-TOF MS technology were performed as previously described [14].

\section{Sequencing of the MCIR gene}

Sequencing of $M C 1 R$ was performed as previously published [10]. MC1R alleles were classified according to the $R$ nomenclature for high penetrance 29insA, D84E, R142H, R151C, R142 R160W and D294H. The low penetrance alleles V60L and V92M were classed as $r[12,20]$.

Table 2: Eye and hair colour of 382 Danes in this study

\begin{tabular}{lcccc}
\hline & Black/brown/dark blond hair & Light blond/fair hair & Red/auburn hair & Totals \\
\hline Blue/grey eyes & 111 & 146 & 11 & 268 \\
\hline Brown/hazel eyes & 51 & 14 & 4 & 29 \\
\hline Green eyes & 28 & 15 & 45 \\
\hline Totals & 190 & 175 & 382 \\
\hline
\end{tabular}




\section{Statistical analysis}

Allele frequencies of categorical data were analysed using Fisher's exact test and odds radios. Quantitative values were analysed using linear regression on SNP allelic counts and SNP effects tested by Walds test using Plink v0.99 [21]. All P-values were corrected by using empirical (adaptive) permutation with standard settings or by using Bonferroni single-step adjusted p-values. Analysis of variance (ANOVA), cluster analysis and discriminant analysis were performed with SYSTAT $^{\circledast}$ v.11. Kruskal-Wallis one way analysis of variance was used to test for differences between male and female $\mathrm{a}^{*}$ values. Linkage disequilibrium ( $\mathrm{D}^{\prime}$ and $\mathrm{R}^{2}$ ) was calculated using Haploview 4.0 [22].

\section{Results}

\section{Quantitative measure of hair colour}

We measured hair colour in the Scottish population using tristimulus colorimetry, which assigns three values; $\mathrm{L}^{*}$ assays the light/dark axis, a* measures red/green and b* indicates yellow/blue. Figure 1 shows all individuals plotted against each pair of parameters $\left(\mathrm{L}^{*} \mathrm{vs} \mathrm{a}^{*}, \mathrm{~L}^{*} \mathrm{vs} \mathrm{b}^{*}\right.$ and $\mathrm{a}^{*}$ vs $\left.\mathrm{b}^{*}\right)$, The values are clearly correlated, as previously reported [23]. The measured hair colours showed L* values ranging from 16.42 to 53.20 (within a maximum range of 0 to 100 , where higher values are lighter). The $\mathrm{a}^{*}$ values ranged from 0.88 to 12.74 and $b *$ values from 0.97 to 19.51 (where positive values indicate increasing red and yellow colour respectively). When viewed plotted in 3 dimensions, against each parameter simultaneously, (Figure 2A) the individual hair colours are distributed in a triangular pattern where individuals with brown hair colour had low $\mathrm{L}^{*}, \mathrm{a}^{*}$ and $\mathrm{b}^{*}$ values and red haired individuals had high $a^{*}$ and $b^{*}$ values and midrange $L^{*}$ values. Individuals with blond hair colour had midrange $\mathrm{a}^{*}$ and high $\mathrm{b}^{*}$ and $\mathrm{L}^{*}$ values. A similar hair colour distribution was previously described [23]. Cluster analysis in two groups of the quantitative measures of hair colour defined a group with dark hair colour with $95 \%$ confidence intervals $L^{*}(16.90 ; 29.80)$, a* $(1.29 ; 6.31)$ and $b^{*}(1.51 ; 10.99)$ which was separated from the red/light hair colour group $L^{*}(26.61,48.61), a^{*}(2.31 ; 11.01)$ and $b^{*}(9.72 ; 19.87)$, but the groups had merging borderlines at all three dimensions $\quad L^{*}(26.61-29.80) / a^{*}(2.31-6.31) / b^{*}(9.72-$ 10.99). Cluster analysis with more than two groups did not correlate with groups as defined by visual inspection. A gender deviation was observed. In females $(\mathrm{N}=85)$, the $\mathrm{a}^{*}$ values were significantly higher than for males $(\mathrm{N}=23)$ $\mathrm{p}=0.018, \mathrm{R}^{2}=0.05$ (Figure $2 \mathrm{~B}$ ). The mean female $\mathrm{a}^{*}$ value is 4.67 and mean male is 3.39 . Using a nonparametric test to test for differences, Kruskal-Wallis chi-squared analysis gives a $\mathrm{P}$ value of 0.003 .

Discriminant analysis showed that the hair colours assigned as blond by inspection were correctly assigned in $85 \%(\mathrm{~N}=22)$ of the individuals, whereas dark (black, brown) was correctly assigned in $94 \%(\mathrm{~N}=61)$. Red hair
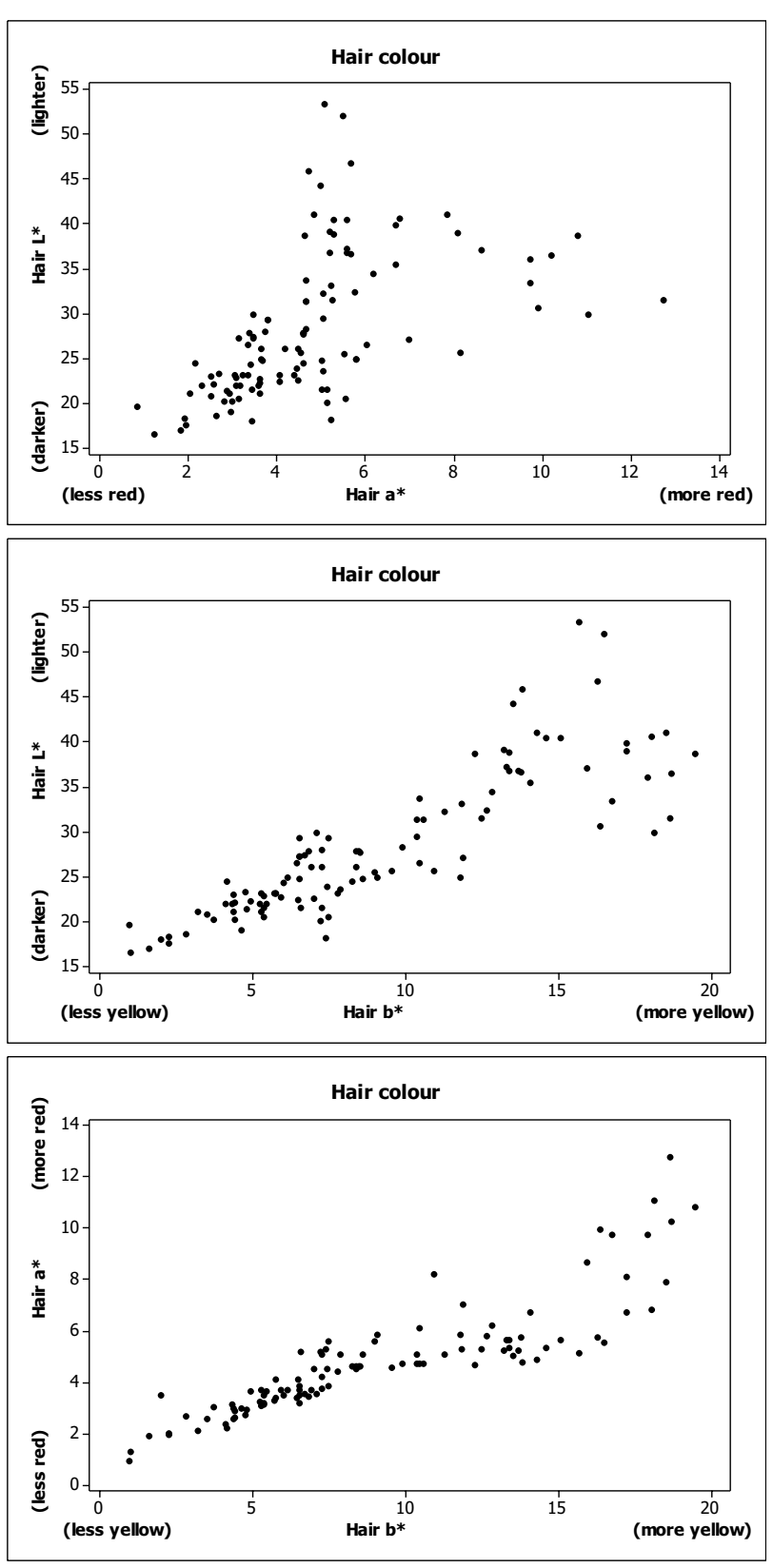

\section{Figure I}

L*(dark/light) $\mathbf{a} *$ (red) $b *($ yellow) values (hair colour) measured by tristimulus colorimetry in 107 Scots from Edinburgh. Each individual is plotted as $L^{*}$ vs $a^{*}$ (top), L* vs b* (middle) and $\mathbf{a}^{*}$ vs b* (bottom).

colour was correctly assigned in $86 \%(\mathrm{~N}=6)$ of the individuals whereas auburn hair colour was classified correctly in only $22 \%(\mathrm{~N}=2)$ and alternatively defined as either blond $(\mathrm{N}=1)$, brown $(\mathrm{N}=3)$ or red $(\mathrm{N}=3)$.

Chi-square analysis of the hair and eye colour categories (Table 1 and 2) indicates that these are not independent and blue/grey eyes are more often found with fair or 
blond hair and brown/hazel eyes with dark hair. (Scots, $\mathrm{X}^{2}=34.41$, 9 d.o.f., $\mathrm{P}<0.001$; Danes, $\mathrm{X}^{2}=29.33$, 6 d.o.f., $\mathrm{P}<0.001)$

\section{SNP Associations with Hair and Eye Colour}

107 individuals from the Scottish cohort were typed at 384 SNPs from 33 genes. Choice of SNPs was guided by HapMap so that each gene was represented by tagging SNPs. In addition the MC1R gene was sequenced from each individual and any variants found categorised as $R$ (high penetrant red hair) or $r$ (low penetrant red hair). Associations between SNPs and quantitative tristimulus values were examined using linear regression and $p$-values for putative associations were corrected using permutation or by Bonferroni adjustment. Table 3 shows SNPs in 11 genes in which SNPs were found with adjusted p-values of $<0.05$. Associations of the same 384 SNPs with eye colour were also analysed in the same 107 Scottish individuals, using Fisher's exact test on the categorical data (Table 4). All association data is tabulated in additional material [see Additional file 2]. The Danish population was initially typed at SNPs in 4 genes previously indicated to have associations with hair colour (SLC45A2, HERC2, OCA2 and MC1R) across 378 individuals, and associations tested with dark versus light hair (Table 5). A subset of 210 Danes was further analysed to follow up significant associations found in the Scottish population (Table 6). The size of these sample populations mean that for alleles of low frequency the power to detect associations is limited, unless the effect is large.

\section{The KITLG gene and hair colour}

In the Scottish population, the three SNPs, rs 1492354 (p $=0.0009), \operatorname{rs} 1907702(\mathrm{p}=0.018)$ and $\mathrm{rs} 10777129(\mathrm{p}=$ 0.007 ) located in intron 1 of the KITLG gene were significantly associated with hair colour (Table 3 ). Of the three SNPs, the rs1492354 AG genotype showed the highest contribution to both the red hair colour dimension $\mathrm{a}^{*}$ values $\left(P<0.001, R^{2}=0.119\right)$ and the yellow hair colour dimension $b^{*}$ values $\left(p=0.001, R^{2}=0.103\right)$, the latter value was significant when uncorrected by permutations. The $\mathrm{L}^{*}$ axis also showed a trend towards lighter hair colour associated with the A genotype, although this is not statistically significant (Figure 3 ). Associations were also found between hair colour ( $\mathrm{a}^{*}$ values) and the two other intron 1 SNPs, rs 1907702 and rs 10777129 . All three SNPs are in linkage disequilibrium in the population, with $\mathrm{D}^{\prime}$ and $\mathrm{r}^{2}$ values as follows: rs1492354 and rs1907702 $\left(\mathrm{D}^{\prime}=\right.$ 1.0, $\left.\mathrm{r}^{2}=0.33\right), \mathrm{rs} 1492354$ and $\mathrm{rs} 10777129\left(\mathrm{D}^{\prime}=0.88, \mathrm{r}^{2}\right.$ $=0.74)$, rs1907702 and rs10777129 $\left(D^{\prime}=1.0, r^{2}=0.34\right)$

When retyped in the Danish population, the SNPs rs10777129 ( $\mathrm{p}=0.02, \mathrm{OR}=3.0)$ and $\mathrm{rs} 1492354 \mathrm{~A}(\mathrm{p}=$ $0.04, \mathrm{OR}=2.5$ ) were significantly associated with light hair colour (Table 4). In both the Scottish and the Danish populations, the alleles associated with lighter colour had similar low frequency (rs1492354: 0.08 and rs10777129: 0.07 ), and given the sample sizes only one homozygote rs10777129 GG was observed, in a Dane.

\section{The OCA2 gene and eye and hair colour}

SNPs in or close to the OCA2 gene have been reported to be associated with hair and eye colour. However, reported associations are with different regions of the gene; including coding variations and SNPs within the adjacent HERC2. In the Scottish population, associations between eye colour and tagging SNPs were found for SNPs in introns 1, 2, 4, 6, 16, 18 and 23 of OCA2 (Table 4). Associations with hair colour were also found for some of these same SNPs, and others, located in introns 1, 2, 4, 5, 19 and 23 (Table 3). The intron 1 SNPs rs7495174 ( $\mathrm{p}=$ $\left.0.02, \mathrm{R}^{2}=0.051\right)$ and $\operatorname{rs} 7174027\left(\mathrm{p}=0.005, \mathrm{R}^{2}=0.075\right)$ were associated with the $\mathrm{L}^{*}$ values, whereas SNPs in intron 2, 4, 5 and 19 were associated exclusively or more strongly with the $\mathrm{a}^{*}$ values. The majority of SNPs associated with hair colour were located in intron 23 and SNPs in this intron were associated with both $\mathrm{a}^{*}$ and $\mathrm{L}^{*}$ values. The markers with the highest correlation were found in intron 23 for rs6497233 ( $\left.\mathrm{p}=0.0004, \mathrm{R}^{2}=0.116\right)$ and rs11631195 ( $\left.\mathrm{p}=0.0002, \mathrm{R}^{2}=0.126\right)$ (Table 3). Subsequently, analysis of variance of the rs 11631195 AA versus the AG and GG collapsed genotypes showed significant association on the black/white dimension $\mathrm{L}^{*}$ value $(\mathrm{p}=$ $\left.0.001, \mathrm{R}^{2}=0.094\right)$, the red dimension, $\mathrm{a}^{*}$ value $(\mathrm{p}=$ $\left.0.009, \mathrm{R}^{2}=0.064\right)$ and the yellow dimension, $\mathrm{b}^{*}$ value $(\mathrm{p}$ $\left.=0.001, \mathrm{R}^{2}=0.107\right) . \mathrm{LD}$ analysis of the data reveals that in this population the SNPs in introns 1 to 5 are in linkage disequlibrium, as are those in introns 19 to 23 (data not shown). Thus there appears to be two separate regions of association with hair and eye colour in the OCA2 gene.

As we and others have previously published, a SNP in a putative regulatory element for OCA2, located about 20 $\mathrm{kb}$ upstream within the HERC2 gene, is associated with eye colour [4][5][6,7] and hair colour [4]. In the Danish population $(\mathrm{N}=378)$ analysed here, a significant association was also observed between dark hair colour and SNPs in HERC2 (rs916977, rs1129038, rs2238289 and rs7170852) $\left(\mathrm{p}=2.0 \times 10^{-6}-8.3 \times 10^{-5}, \mathrm{OR}=3.5-4.0\right)$. However, the OCA2 coding SNPs R419Q (rs1800407) and R305W (rs1800401) were not significantly associated with hair colour (Tables 5), although the minor allele frequencies were low (0.04 for each) which limits the power to detect associations in populations of this size.

\section{The MCIR gene and hair colour}

Sequence variations in MC1R in the Scottish population were categorized into the two allelic groups $R$ and $r$. The $R$ group was significantly associated $\left(\mathrm{p}=2.0 \times 10^{-6}\right.$, single step adjusted Bonferroni corrections) with high correlation with $\mathrm{a}^{*}$-values $\left(\mathrm{R}^{2}=0.317\right)$ that are characteristic of red hair colour. The MC1 $R$ ' $r$ ' group was significantly asso- 
Table 3: Associations between SNP alleles with minor allele frequencies and quantitative measures of the hair colours ( $L * a * b *$ values) with $P<0.05$ in 107 Scots from Edinburgh.

\begin{tabular}{|c|c|c|c|c|c|c|c|c|c|c|c|c|}
\hline Gene & Chr. & Position $^{a}$ & SNP & $\begin{array}{l}\text { Min. } \\
\text { allele }\end{array}$ & MAFb & $\begin{array}{c}\mathrm{L}^{*} \\
\text { p-value }\end{array}$ & $\begin{array}{l}\mathbf{L}^{*} \\
\mathbf{R}^{\mathbf{2}}\end{array}$ & $\begin{array}{c}\mathbf{a}^{*} \\
\text { p-value }\end{array}$ & $\begin{array}{l}\mathbf{a}^{*} \\
\mathbf{R}^{2}\end{array}$ & $\begin{array}{c}\mathbf{b}^{*} \\
\text { p-value }\end{array}$ & $\begin{array}{l}\mathbf{b}^{*} \\
\mathbf{R}^{\mathbf{2}}\end{array}$ & Hair colour \\
\hline \multirow[t]{5}{*}{ HPS3 } & 3 & Int I.I & rs468II69 & $A$ & 0.30 & & & 0.046 & 0.039 & & & Dark \\
\hline & & Int 1.2 & rs 16861514 & $\mathrm{~T}$ & 0.15 & & & 0.043 & 0.039 & & & Dark \\
\hline & & Int 6 & rs 16861552 & C & 0.33 & & & 0.021 & 0.054 & & & Dark \\
\hline & & Int 8 & rs6785780 & $\mathrm{T}$ & 0.41 & & & 0.003 & 0.079 & & & Red/Light \\
\hline & & Int 13 & rs7636389 & A & 0.07 & & & 0.026 & 0.049 & & & Red/Light \\
\hline DTNBPI & 6 & $\begin{array}{l}\text { Exon } 10 \\
\text { (S272P) }\end{array}$ & rs 17470454 & A & 0.05 & 0.011 & 0.060 & & & 0.011 & 0.044 & Light \\
\hline TYRPI & 9 & $\operatorname{lnt} 6$ & rs 17346161 & $\mathrm{~T}$ & 0.06 & & & 0.046 & 0.037 & & & Red/Light \\
\hline \multirow[t]{2}{*}{$E R C C 6$} & 10 & $\operatorname{lnt} 5$ & rsI0I8603 & C & 0.11 & 0.041 & $0.04 I$ & & & $0.04 I$ & 0.038 & Dark \\
\hline & & $\operatorname{lnt} 9$ & rs4253162 & $A$ & 0.07 & 0.011 & 0.058 & & & 0.011 & 0.060 & Dark \\
\hline \multirow[t]{3}{*}{ KITLG } & 12 & Int I.I & rs|492354 & A & 0.07 & & & $0.0009 d$ & 0.119 & & & Red/Light \\
\hline & & Int 1.2 & rs1907702 & G & 0.20 & & & 0.018 & 0.05 & & & Red/Light \\
\hline & & Int 1.3 & rs $10777 \mid 29$ & $A$ & 0.08 & & & 0.007 & 0.06 & 0.043 & 0.080 & Red/Light \\
\hline \multirow[t]{20}{*}{ OCA2 } & 15 & Int I.I & rs7495I74 & G & 0.05 & 0.02 & 0.051 & & & 0.024 & 0.040 & Dark \\
\hline & & Int 1.2 & rs7I74027 & A & 0.06 & 0.005 & 0.075 & & & 0.005 & 0.060 & Dark \\
\hline & & Int 2.1 & rs $12442 \mid 47$ & C & 0.11 & 0.03 & 0.041 & 0.010 & 0.066 & 0.03 & 0.065 & Dark \\
\hline & & Int 2.2 & rs 12324648 & A & 0.07 & & & 0.019 & 0.057 & & & Dark \\
\hline & & Int 2.3 & rs|470608 & A & 0.10 & & & 0.012 & 0.063 & & & Dark \\
\hline & & $\operatorname{lnt} 4$ & rs3794604 & A & 0.08 & & & 0.031 & 0.042 & & & Dark \\
\hline & & $\operatorname{lnt} 5$ & rs749846 & A & 0.11 & & & 0.025 & 0.054 & & & Dark \\
\hline & & Int 19 & rs1375I66 & A & 0.20 & & & 0.046 & 0.039 & & & Dark \\
\hline & & Int 23.I & rs231I470 & C & 0.50 & & & 0.005 & 0.073 & & & Dark \\
\hline & & Int 23.2 & rsII858340 & A & 0.44 & & & 0.016 & 0.053 & & & Red/Light \\
\hline & & Int 23.3 & rs6497235 & A & 0.50 & 0.03 & 0.050 & 0.006 & 0.069 & 0.03 & 0.063 & Light \\
\hline & & Int 23.4 & rsII074306 & $A$ & 0.41 & & & 0.024 & 0.048 & & & Dark \\
\hline & & Int 23.5 & rs6497233 & $\mathrm{T}$ & 0.41 & 0.02 & 0.053 & $0.0004 \mathrm{e}$ & 0.116 & 0.021 & 0.098 & Light \\
\hline & & Int 23.6 & rs 17674017 & G & 0.42 & & & 0.005 & 0.073 & & & Red/Light \\
\hline & & Int 23.7 & rs|498509 & C & 0.49 & & & 0.010 & 0.060 & & & Dark \\
\hline & & Int 23.8 & rsl|631/95 & A & 0.37 & 0.004 & 0.079 & $0.0002^{d}$ & 0.126 & $0.0037 c$ & 0.130 & Light \\
\hline & & Int 23.9 & rs3947367 & G & 0.29 & 0.012 & 0.059 & & & 0.012 & 0.039 & Light \\
\hline & & Int 23.10 & rsl|6375I8 & G & 0.35 & 0.014 & 0.051 & 0.009 & 0.064 & 0.014 & 0.078 & Light \\
\hline & & Int 23.1I & rs989869 & C & 0.38 & 0.008 & 0.063 & & & 0.0077 & 0.053 & Dark \\
\hline & & Int 23.12 & rsI603784 & A & 0.23 & 0.007 & 0.063 & & & 0.0069 & 0.041 & Dark \\
\hline \multirow[t]{6}{*}{ MYO05 } & 15 & Int I.I & rs1615028 & C & 0.17 & 0.046 & 0.037 & & & & & Light \\
\hline & & Int 1.2 & rsI724593 & G & 0.15 & 0.012 & 0.059 & & & 0.012 & 0.066 & Light \\
\hline & & Int 1.3 & rs7I7606I & $C$ & 0.48 & 0.046 & $0.04 I$ & & & & & Dark \\
\hline & & $\operatorname{lnt} 2$ & rs 1724625 & $\mathrm{~T}$ & 0.30 & 0.036 & 0.044 & & & & & Light \\
\hline & & $\operatorname{lnt} 5$ & rs 1724630 & G & 0.21 & 0.049 & 0.039 & & & 0.049 & 0.040 & Light \\
\hline & & Int 9 & rsl632403 & $\mathrm{T}$ & 0.08 & 0.042 & 0.039 & & & 0.042 & 0.049 & Light \\
\hline
\end{tabular}


Table 3: Associations between SNP alleles with minor allele frequencies and quantitative measures of the hair colours (L*a*b* values) with $P<0.05$ in 107 Scots from Edinburgh. (Continued)

\begin{tabular}{|c|c|c|c|c|c|c|c|c|c|c|c|c|}
\hline$M C I R$ & 16 & $\begin{array}{l}\text { Exon } \\
\text { Exon }\end{array}$ & $\begin{array}{l}R \\
r\end{array}$ & $\begin{array}{l}\text { None } \\
\text { None }\end{array}$ & $\begin{array}{l}0.21 \\
0.23\end{array}$ & & & $\begin{array}{c}2.00 \times 10^{-6 c} \\
0.005\end{array}$ & $\begin{array}{c}0.317 \\
0.07\end{array}$ & $0.047^{c}$ & 0.156 & $\begin{array}{c}\text { Red } \\
\text { Dark/Light }\end{array}$ \\
\hline \multirow[t]{2}{*}{ PRKARIA } & 17 & Int 2 & rs2952275 & $\mathrm{T}$ & 0.36 & 0.047 & 0.036 & & & & & Light \\
\hline & & 5' UTR & rs8080306 & C & 0.27 & 0.021 & 0.047 & & & & & Light \\
\hline \multirow[t]{3}{*}{ GNAS } & 20 & Int 3 & rs2295583 & $\mathrm{T}$ & 0.28 & 0.03 & 0.43 & & & & & Light \\
\hline & & Int 5 & rs3730168 & A & 0.41 & 0.015 & 0.052 & & & & & Dark \\
\hline & & Int 6 & rs919197 & $\mathrm{T}$ & 0.43 & 0.006 & 0.07 & & & 0.0062 & 0.059 & Light \\
\hline \multirow[t]{2}{*}{ HPS4 } & 22 & Int 2 & rs9613187 & $\mathrm{T}$ & 0.11 & 0.012 & 0.059 & & & 0.012 & 0.037 & Light \\
\hline & & Int 5 & rs $1740 \mid 652$ & $\mathrm{~T}$ & 0.10 & & & 0.028 & 0.047 & & & Red/Light \\
\hline
\end{tabular}

a: Intron (Int), Exon or Untranslated region (UTR) position in the gene

b: Minor allele frequency (MAF)

c: Significant using Bonferroni correction. Other $\mathrm{L}^{*}, \mathrm{a}^{*}$ and $\mathrm{b}^{*}$ values were corrected using empirical permutations

d: Significant using False Discovery Rate correction

ciated with low $\mathrm{a}^{*}$-values $\left(\mathrm{p}=0.005, \mathrm{R}^{2}=0.007\right)$ when $R$ and consensus sequences were collapsed. Analysis of variance of the $M C 1 R R / R$ genotype showed significant association for both the red dimension, $\mathrm{a}^{*}$ value $(\mathrm{P}<0.001$, $\left.\mathrm{R}^{2}=0.367\right)$ and the yellow dimension, $\mathrm{b}^{*}$ value $(\mathrm{P}<$ $\left.0.001, R^{2}=0.163\right)$. No association was seen with the $L^{*}$, light-dark, dimension. In addition, the Danish population excluded individuals with red hair, which permitted an analysis of association between individual $M C 1 R$ variants and light hair. No association was seen, reinforcing the notion that $M C 1 R$ affects the colour but not the intensity of hair pigmentation.

\section{The HPS3 gene and hair colour}

We initially identified in the Scottish population a hitherto unreported association between the HPS3 gene and the red/yellow colour axes. Five SNPs (rs4681169, rs16861514, rs16861552, rs6785780 and rs7636389), all in LD in this population, were significantly associated with the red dimension $\mathrm{a}^{*}$ value of which rs6785780 (p = $0.003, R^{2}=0.079$ ) was the most strongly associated (Table $3)$. When replicated initially in a subset $(\mathrm{N}=210)$ of the Danish population, the association between the rs6785780 T allele and light hair colour was also significant $(\mathrm{p}=0.04, \mathrm{OR}=1.6)$ (Table 4). However, an extended analysis of this SNP on the larger $(\mathrm{N}=378)$ Danish population failed to find an association. Our data do not, therefore, support a role for HPS3 in hair colour variation, but suggest that it may be worth further investigation.

\section{The TYR and SLC45A2 genes and hair colour}

SNPs within the tyrosinase (TYR) and the SLC45A2 (MATP)genes have previously been shown to associate with hair colour $[15,16]$. We therefore paid particular attention to these genes in our populations. The SNP rs12421746 in the TYR gene was significantly associated with blond hair colour in the Danish population ( $\mathrm{p}=$ $0.04, \mathrm{OR}=3.1$ ) (Table 6), but we did not replicate this association with any of the colorimetric values in the Scottish population. In the Scottish population, the minor allele frequency in TYR was 0.012 while it was 0.04 in the Danish population. Again this low allele frequency will restrict the ability to detect small effects in a population sample of the size studied here.

Likewise, no statistically significant association was observed between tagging SNPs in SLC45A2 and hair colour in the Scottish population, whereas in the Danish population $(\mathrm{N}=378)$, the one coding SNP rs 16891982 $(\mathrm{F} 374 \mathrm{~L})(\mathrm{p}=0.005, \mathrm{OR}=7.0)$ was associated with dark hair colour (Table 5).

\section{Discussion}

We have used quantitative hair colour on a tristimulus $\mathrm{L}^{*}$, $\mathrm{a}^{*}$ and $\mathrm{b}^{*}$ scale not only to associate genetic markers to hair colour, but also to evaluate the accuracy of the inspected hair colours. The two clusters of light or dark hair colour based on colorimetric analysis were well separated and good correlation was observed between inspections (88-94\%) and quantitative hair measures. Further sub-classification of these groups did not satisfactorily correlate with the groupings. Shekar and co-workers observed $97 \%$ correct classification in two groups whereas only $73.1 \%$ were correctly assigned using observer reported colour in six groups [2]

In total, robust associations between hair colour and five genes MC1R, KITLG, TYR, OCA2 and SLC45A2 were observed. SNPs in or close to all of these have previously been reported by others as showing associations. 
Table 4: Associations between SNP alleles with minor allele frequencies and eye colour categorised from photos of 107 Scots from Edinburgh.

\begin{tabular}{|c|c|c|c|c|c|c|c|c|c|c|c|c|}
\hline \multirow[t]{2}{*}{ Gene } & \multirow[t]{2}{*}{ Chr } & \multirow[t]{2}{*}{ SNP } & \multirow[t]{2}{*}{ position $^{a}$} & \multirow[t]{2}{*}{ Min A } & \multirow[t]{2}{*}{ MAFb } & \multirow{2}{*}{$\begin{array}{c}\text { Ranked Eye colours } \\
\text { p-values }\end{array}$} & \multicolumn{2}{|c|}{ Shades } & \multicolumn{2}{|c|}{ Brown vs blue } & \multicolumn{2}{|c|}{ Brown vs other } \\
\hline & & & & & & & p-values & OR & p-values & OR & p-values & OR \\
\hline HPS3 & 3 & $\begin{array}{l}\text { rs7643410 } \\
\text { rs22549I3 } \\
\text { rs2689229 } \\
\text { rs2689230 } \\
\text { rs2689234 } \\
\text { rs6785780 } \\
\text { rs2681092 }\end{array}$ & $\begin{array}{l}\text { int I } \\
\text { int } 5.1 \\
\text { int } 5.2 \\
\text { int } 5.3 \\
\text { int } 6 \\
\text { int } 8 \\
\text { int } 15\end{array}$ & $\begin{array}{l}G \\
A \\
A \\
G \\
G \\
T \\
T\end{array}$ & $\begin{array}{l}0.08 \\
0.37 \\
0.46 \\
0.23 \\
0.49 \\
0.41 \\
0.38\end{array}$ & $\begin{array}{l}0.006 \\
0.01 \\
0.04 \\
0.03 \\
0.03 \\
0.02\end{array}$ & $\begin{array}{c}0.03 \\
0.02 \\
0.046\end{array}$ & $\begin{array}{l}1.7 \\
1.8 \\
2.2\end{array}$ & $\begin{array}{c}0.003 \\
0.004 \\
0.02 \\
0.009 \\
0.02 \\
0.01\end{array}$ & $\begin{array}{l}2.6 \\
2.5 \\
2.6 \\
2.3 \\
2.3 \\
2.3\end{array}$ & $\begin{array}{l}0.04 \\
0.01 \\
0.04\end{array}$ & $\begin{array}{l}2.9 \\
1.9\end{array}$ \\
\hline KIT & 4 & rs 17084733 & 3' UTR & $A$ & 0.11 & & & & 0.02 & 4.3 & 0.04 & 3.6 \\
\hline DTNBPI & 6 & rs9476886 & int I & $\mathrm{T}$ & 0.28 & & & & 0.04 & 2.4 & & \\
\hline \multirow[t]{2}{*}{$E R C C 8$} & 5 & rs4647I 28 & int 10 & G & 0.03 & 0.04 & 0.02 & 6.1 & & & & \\
\hline & & rs4235483 & int 9 & A & 0.44 & & 0.04 & 1.7 & & & & \\
\hline$E R C C 6$ & 10 & rs425323I & 3'UTR & C & 0.09 & 0.007 & 0.003 & 3.6 & 0.08 & 2.8 & 0.01 & 3.0 \\
\hline CYP2C8 & 10 & rsII572I77 & int 8 & G & 0.30 & & & & & & 0.04 & 1.9 \\
\hline$D C T$ & 13 & rs9584233 & int 6 & $\mathrm{~T}$ & 0.11 & & & & 0.03 & 3.4 & 0.03 & 2.4 \\
\hline \multirow[t]{7}{*}{ OCA2 } & 15 & $\begin{array}{l}\text { rs7495I74 } \\
\text { rs7174027 }\end{array}$ & $\begin{array}{l}\text { int } 1.1 \\
\text { int } 1.2\end{array}$ & $\begin{array}{l}\mathrm{G} \\
\mathrm{A}\end{array}$ & $\begin{array}{l}0.05 \\
0.06\end{array}$ & $\begin{array}{l}0.001^{d} \\
0.009\end{array}$ & 0.006 & $\begin{array}{l}6.3 \\
3.1\end{array}$ & $\begin{array}{l}0.003 \\
0.003\end{array}$ & $\begin{array}{l}\text { NA } \\
\text { NA }\end{array}$ & $\begin{array}{l}0.009 \\
0.03\end{array}$ & $\begin{array}{l}5.9 \\
3.3\end{array}$ \\
\hline & & $\begin{array}{l}\text { rs7179994 } \\
\text { rsI597196 } \\
\text { rsI470608 } \\
\text { rs } 12324648\end{array}$ & $\begin{array}{l}\text { int } 2.1 \\
\text { int } 2.2 \\
\text { int } 2.3 \\
\text { int } 2.4\end{array}$ & $\begin{array}{l}\mathrm{G} \\
\mathrm{T} \\
\mathrm{A} \\
\mathrm{A}\end{array}$ & $\begin{array}{l}0.14 \\
0.15 \\
0.10 \\
0.07\end{array}$ & $\begin{array}{l}0.03 \\
0.008 \\
0.006\end{array}$ & $\begin{array}{l}0.03 \\
0.04\end{array}$ & $\begin{array}{l}2.0 \\
2.9\end{array}$ & $\begin{array}{l}0.03 \\
0.008 \\
0.009\end{array}$ & $\begin{array}{l}3.1 \\
3.6 \\
5.2\end{array}$ & $\begin{array}{l}0.04 \\
0.02 \\
0.046 \\
0.004\end{array}$ & $\begin{array}{l}2.3 \\
2.4 \\
2.3 \\
4.1\end{array}$ \\
\hline & & rs3794604 & int 4 & $A$ & 0.08 & 0.03 & & 2.5 & 0.04 & 3.8 & 0.006 & 3.7 \\
\hline & & rs74686I & int 6 & C & 0.45 & & 0.02 & 1.8 & & & & \\
\hline & & rs7176632 & int 16 & $\mathrm{~T}$ & 0.18 & 0.0003 & 0.0008 & 2.9 & 0.0008 & 5.0 & 0.01 & 2.3 \\
\hline & & $\begin{array}{l}\text { rs7173419 } \\
\text { rs } 2594938 \\
\text { rs|562592 } \\
\text { rsI448490 }\end{array}$ & $\begin{array}{l}\text { int } 18.1 \\
\text { int } 18.2 \\
\text { int } 18.3 \\
\text { int } 18.4\end{array}$ & $\begin{array}{l}\mathrm{T} \\
\mathrm{C} \\
\mathrm{T} \\
\mathrm{A}\end{array}$ & $\begin{array}{l}0.27 \\
0.26 \\
0.17 \\
0.16\end{array}$ & $\begin{array}{c}0.01 \\
0.01 \\
5.21 \times 10^{-5 d} \\
0.03\end{array}$ & $\begin{array}{c}0.02 \\
0.02 \\
4.12 \times 10-5 d \\
0.02\end{array}$ & $\begin{array}{l}2.1 \\
2.0 \\
3.7 \\
2.8\end{array}$ & $\begin{array}{l}0.046 \\
0.02 \\
0.0009 \\
0.009\end{array}$ & $\begin{array}{l}2.2 \\
2.3 \\
4.2 \\
7.0\end{array}$ & $\begin{array}{l}0.0009 \\
0.002\end{array}$ & $\begin{array}{l}2.9 \\
8.6\end{array}$ \\
\hline & & $\begin{array}{c}\text { rsl76740I7 } \\
\text { rsl498509 } \\
\text { rsl } 1631195 \\
\text { rs } 989869 \\
\text { rsl603784 } \\
\text { rsl I074304c }\end{array}$ & $\begin{array}{l}\text { int } 23.1 \\
\text { int } 23.2 \\
\text { int } 23.3 \\
\text { int } 23.4 \\
\text { int } 23.5 \\
\text { int } 23.6\end{array}$ & $\begin{array}{l}\text { G } \\
C \\
A \\
C \\
A \\
A\end{array}$ & $\begin{array}{l}0.42 \\
0.49 \\
0.37 \\
0.38 \\
0.23 \\
0.42\end{array}$ & $\begin{array}{l}0.008 \\
0.03 \\
0.04 \\
0.02 \\
0.01 \\
0.04\end{array}$ & 0.04 & 1.9 & $\begin{array}{l}0.03 \\
0.04 \\
0.04 \\
\\
0.03 \\
0.04\end{array}$ & $\begin{array}{l}2.2 \\
2.0 \\
2.0 \\
\\
2.6 \\
2.2\end{array}$ & & \\
\hline GNAS & 20 & rs 4810147 & int I & A & 0.49 & 0.02 & & & 0.004 & 2.6 & 0.04 & 1.8 \\
\hline
\end{tabular}

a: Intron (Int), Exon or Untranslated region (UTR) position in the gene

b: Minor allele frequency (MAF)

c: alleles slightly out of Hardy Weinberg Equilibrium

$\mathrm{d}$ : Significant using Bonferroni correction. Other p-values were corrected by empirical permutation

e: Significant association in Duffy et al. 2006

NA: No answer. Only observed among individuals with brown eye colour 
MC1R is a melanocyte-specific G-protein coupled receptor for alpha-melanocyte stimulating hormone and is well established as the major determinant of red hair colour [9][10][11][12][13]. Among the numerous variants, those classified as " $R$ " are highly penetrant red-hair alleles. In the Scottish population the MC1R R/R genotype showed the strongest contribution to the variance of the red/yellow correlated dimensions $\mathrm{a}^{*}\left(\mathrm{r}^{2}=0.367\right) / \mathrm{b}^{*}\left(\mathrm{r}^{2}=0.163\right)$ (Table 3).

Associations with the $\mathrm{a}^{*}$ dimensions were also observed with SNPs in intron 1 of the KITLG gene. In both the Scottish and Danish populations. Another SNP near to the KITLG gene, rs12821256, has also been shown to be associated with hair colour in European populations from Iceland, Netherlands and The United States $[4,15]$. This SNP is located several hundreds of kilobases $5^{\prime}$ of the KITLG gene and does not appear to be in LD with those we have analysed in intron $1\left(D^{\prime}=1, r^{2}=0.01\right)$. Unfortunately this SNP was not typed in our populations and so we are unable to determine whether those we analysed show a better correlation with hair colour than this previously reported one. KITLG encodes stem cell factor, the ligand of the KIT receptor which is essential for normal melanocyte proliferation and development [24]. Mutations of KITLG in mice result in deficits in melanocytes and unpigmented patches in the skin and hair and it is not unreasonable to expect that variation in expression or function of the gene in humans could result in variation of melanocyte number in the hair follicles.

The OCA2 gene was first identified in mice, in which mutations of the gene result in a pale coat, and was later shown to be identified in patients with tyrosinase-positive albinism. The function of the gene product is not unequivocally established, but it is related to a transporter protein family which has 12 transmembrane domains and is localised to the melanosome [25]. Associations of OCA2 and HERC2 SNPs with hair and eye colour were found in this study, in accordance with previous reports of linkage or association [3],[4],[5],[6],[7]. The major contribution to eye colour was conveyed by two HERC2 SNPs, rs1129038 and rs129138332, which lie about $20 \mathrm{~kb}$ upstream of the OCA2 gene, and which were almost in perfect linkage disequilibrium $[5,6]$. Association was observed between hair colour and rs1129038 in the Danish population $\left(\mathrm{p}=2.0 \times 10^{-6}, \mathrm{OR}=3.5\right)$, but two SNPs rs2238289 and rs916977 that were in completely linkage disequilibrium with rs $1129038\left(D^{\prime}=1, R^{2}=0.62\right.$ and $D^{\prime}$ $\left.=1, \mathrm{R}^{2}=0.64\right)$ were slightly more strongly associated with dark hair colour $\left(\mathrm{p}=8.3 \times 10^{-5}, \mathrm{OR}=3.7\right.$ and $\mathrm{p}=2.2 \times 10^{-}$

5 , $\mathrm{OR}=4.0$ ). These results support earlier results from

Table 5: Associations between SNP alleles and dark versus light hair colour in 378 Danes.

\begin{tabular}{|c|c|c|c|c|c|c|c|c|}
\hline Gene & Chr. & Position $^{a}$ & SNP & Min.allele & MAFb & p-value & OR $^{\mathbf{e}}$ & Hair colour \\
\hline \multirow[t]{2}{*}{ MATP } & 5 & Exon 5 L374F & rs 16891982 & C & 0.02 & 0.005 & 7.0 & Dark \\
\hline & & $\begin{array}{l}\text { Exon } 3 \\
\text { K272E }\end{array}$ & rs 26722 & A & 0.02 & 0.07 & & Dark \\
\hline \multirow[t]{5}{*}{ HERC2 } & 15 & Int 12 & rs916977c & $\mathrm{T}$ & 0.07 & $8.3 \times 19-5 d$ & 3.7 & Dark \\
\hline & & 3'UTR & rsll $29038^{c}$ & C & 0.11 & $2.0 \times 10^{-6 \mathrm{~d}}$ & 3.5 & Dark \\
\hline & & $\begin{array}{l}\text { Exon } 78 \\
\text { Q3989Q }\end{array}$ & rsII636232 & $\mathrm{T}$ & 0.46 & 0.098 & & \\
\hline & & Int 44 & rs2238289 & G & 0.07 & $2.2 \times 10^{-5 d}$ & 4.0 & Dark \\
\hline & & Int 56 & rs7170852 & $A$ & 0.09 & $1.7 \times 10^{-5} \mathrm{~d}$ & 3.5 & Dark \\
\hline \multirow[t]{2}{*}{ OCA2 } & 15 & $\begin{array}{l}\text { Exon } 9 \\
\text { W305R }\end{array}$ & rsl80040I & $\mathrm{T}$ & 0.04 & 0.75 & & \\
\hline & & Exon $13 \mathrm{Q} 419 \mathrm{R}$ & rs|800407 & $A$ & 0.04 & 0.31 & & \\
\hline \multirow[t]{8}{*}{$M C I R$} & 16 & 5' UTR & rs3212359 & $A$ & 0.34 & 0.17 & & \\
\hline & & 5' UTR & rs321236I & $\mathrm{T}$ & 0.27 & 0.055 & & \\
\hline & & $\mathrm{V} 60 \mathrm{~L}$ & rs|805005 & A & 0.12 & 0.20 & & \\
\hline & & V92M & rs2228479 & A & 0.07 & 0.22 & & \\
\hline & & RI5IC & rs|805007 & $\mathrm{T}$ & 0.09 & 0.70 & & \\
\hline & & RI $60 \mathrm{~W}$ & rs|805008 & $\mathrm{T}$ & 0.08 & 0.055 & & \\
\hline & & RI63Q & rs885479 & $\mathrm{T}$ & 0.04 & 1.0 & & \\
\hline & & $\mathrm{T} 3 \mathrm{I} 4 \mathrm{~T}$ & rs2228478c & G & 0.09 & 1.0 & & \\
\hline
\end{tabular}

a: Intron (Int), Exon or Untranslated region (UTR) position in the gene

b: Minor allele frequency (MAF)

c: alleles slightly out of Hardy Weinberg Equilibrium

$\mathrm{d}$ : Significant using Bonferroni correction. Other p-values were corrected by empirical permutation

e: Odds ratios are only shown for statistically significant associations 
Table 6: Associations between SNP alleles and dark versus light hair colour in 210 Danes.

\begin{tabular}{|c|c|c|c|c|c|c|c|c|}
\hline Gene & Chr. & Position $^{\mathrm{a}}$ & SNP & Min. allele & MAFb & Fisher's Exact & $\mathbf{O R}^{\mathbf{d}}$ & Hair colour \\
\hline \multirow[t]{2}{*}{ HPS3 } & 3 & $\operatorname{lnt} 5$ & rs2254913c & $A$ & 0.45 & 1.00 & & \\
\hline & & Int 8 & rs6785780 & $\mathrm{T}$ & 0.44 & 0.048 & 1.6 & Light \\
\hline \multirow[t]{2}{*}{ DTNBPI } & 6 & $\begin{array}{l}\text { Exon } 10 \\
\text { SI9IP }\end{array}$ & rs 17470454 & A & 0.07 & 0.32 & & \\
\hline & & Int 6 & rs6909929 & A & 0.42 & 0.37 & & \\
\hline$E R C C 6$ & 10 & 3'UTR & rs425323I & C & 0.10 & 0.56 & & \\
\hline CYP2C8 & 10 & Int 8 & rsII572I77 & G & 0.27 & 0.60 & & \\
\hline$T Y R$ & 11 & Int 3 & rs 12421746 & $\mathrm{~T}$ & 0.04 & 0.043 & 3.1 & Light \\
\hline \multirow[t]{2}{*}{ KITLG } & 12 & Int I & rs 10777129 & A & 0.07 & 0.013 & 3.0 & Light \\
\hline & & Int I & rs 1492354 & $A$ & 0.08 & 0.031 & 2.5 & Light \\
\hline$D C T$ & 13 & Int 6 & rs9584233 & $\mathrm{T}$ & 0.12 & 1.00 & & \\
\hline \multirow[t]{3}{*}{ GNAS } & 20 & Int I & rs $4810147 c$ & A & 0.50 & 0.60 & & \\
\hline & & $\operatorname{lnt} 6$ & rs234630 & C & 0.23 & 0.38 & & \\
\hline & & Int 6 & rs919197 & $\mathrm{T}$ & 0.50 & 0.86 & & \\
\hline
\end{tabular}

a: Intron (Int), Exon or Untranslated region (UTR) position in the gene

b: Minor allele frequency (MAF)

c: alleles slightly out of Hardy Weinberg Equilibrium

$\mathrm{d}$ : Odds ratios (OR) are only calculated for statistically significant associations

Shekar and co-workers who demonstrated OCA2 haplotypes to be more strongly associated with hair colour than rs1129038 and rs129138332 [3]. By contrast the strongest association with hair colour in the Scottish population in the OCA2 gene were accounted for by two SNPs in intron 23 on the red dimension $\left(\mathrm{a}^{*}\right)$ rs6497233 $\left(\mathrm{p}=0.0004, \mathrm{R}^{2}\right.$ $=0.116)$ and rs11631195 $\left(\mathrm{p}=0.0002, \mathrm{R}^{2}=0.126\right)$. Linkage disequilibrium was observed between these markers $\left(\mathrm{D}^{\prime}=0.94, \mathrm{R}^{2}=0.79\right)$. The association results from the HERC2/OCA2 region suggest that the molecular mechanism affecting eye colour may not be the same as for hair colour.

Overall in the Danish population, the strongest association with hair colour was observed with the SLC45A2 missense variant $\mathrm{rs} 16891982(\mathrm{OR}=7.0)$ followed by the HERC2 (upstream OCA2) variant rs2238289 $(\mathrm{OR}=4.0)$ and the KITLG variant rs $1492354(\mathrm{OR}=3.0)$. Associations between hair colour and SNPs in TYR and SLC45A2 were only observed in the Danish population. Either of these genes, when mutant in mice or humans, result in albinism. TYR is the rate-limiting enzyme required for melanin synthesis whilst SLC45A2 is a solute transporter whose substrate is unknown [25]. Absence of observed association with these two genes in the Scottish population may well be due to the limited population sizes. The Danish population has power of $82 \%$ to detect at $\mathrm{p}=0.05$ an effect of this TYR SNP with the observed odds ratio of 3.1 and minor allele frequency of 0.04 .

We tentatively suggest a novel association between hair and eye colour and the HPS3 gene. 7 SNPs across the whole gene showed significant association in the Scottish population. However, although initially replicated in a subset of the Danish population when extended to the whole sample we no longer detect association. HPS3 belongs to a group of genes that are involved in biogenesis and/or maturation of multiple cellular organelles including lysosomes and melanosomes, the site of melanin synthesis and export. In the mouse, at least seventeen genes have been identified as HPS like genes, with a mutant phenotype comprising reduced pigmentation and a long bleeding time [26]. Seven of these genes have been demonstrated to be mutated in forms of the inherited, human disorder Hermansky-Pudlack syndrome (HPS), which is a syndrome with multiple disorders including oculocutaneous albinism, bleeding tendency and lysosomal dysfunction [27]. Patients with HPS type 3, and mutant in HPS, 


\section{A}

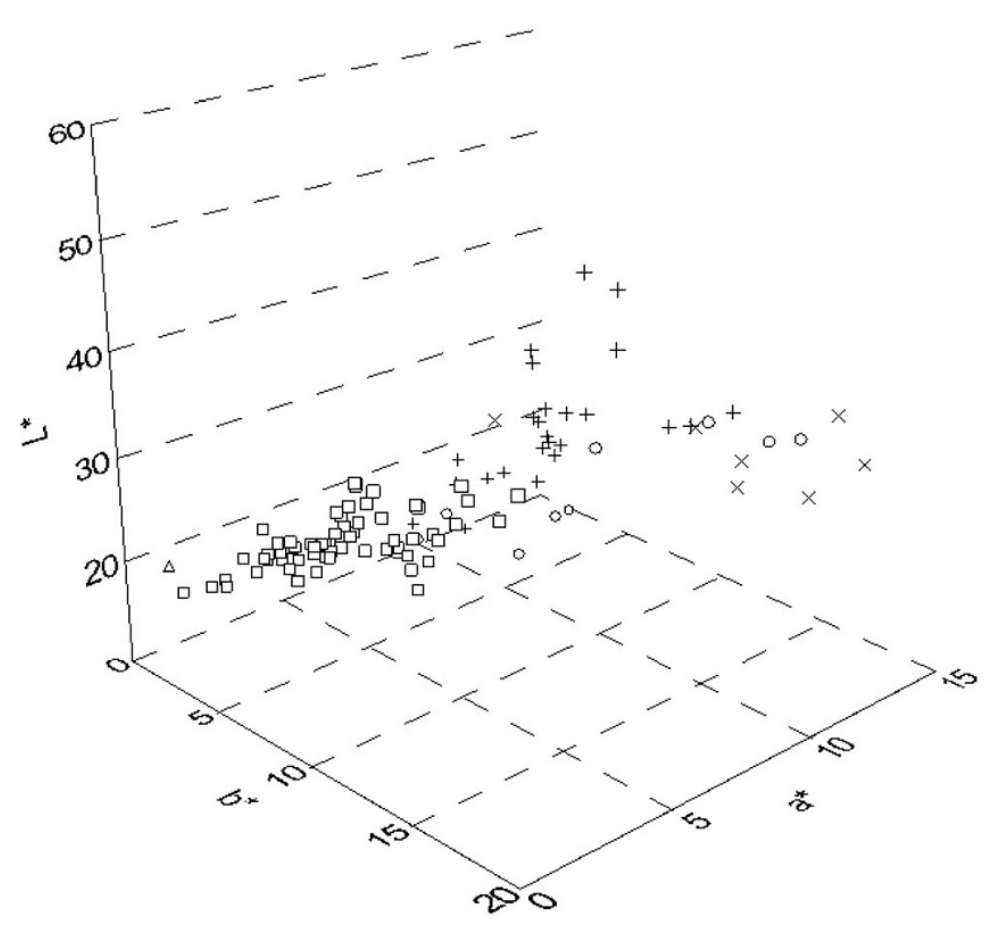

$\mathrm{B}$

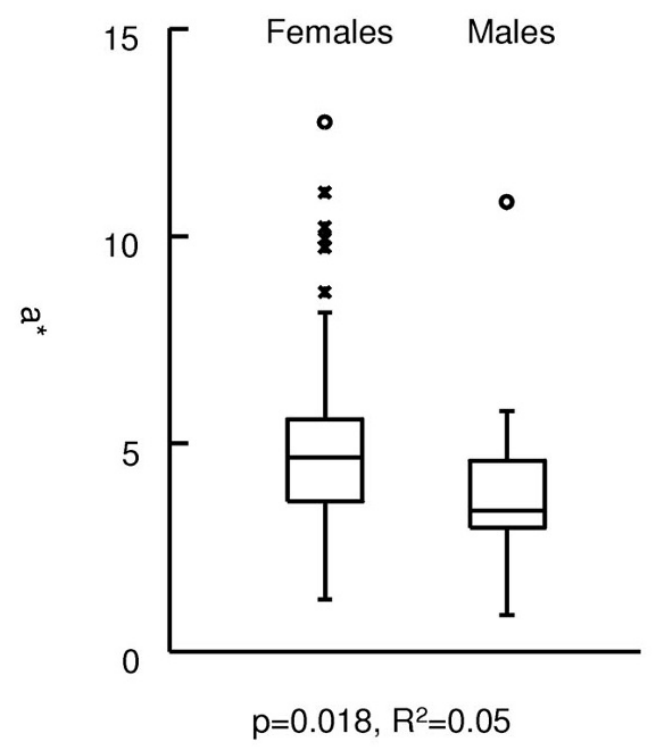

Figure 2

$€$

A: $L *($ dark/light) $a *($ red) $b *($ yellow) values (hair colour) plotted in 3D colour space. The observer report of hair colours were categorised as black $(\triangle)$, brown $(€)$, blonde $(+)$, red $(X)$ and auburn $(O)$. B: Box plot of a* distribution among males and females. Significant deviation of the means was calculated using ANOVA. 
KITLG

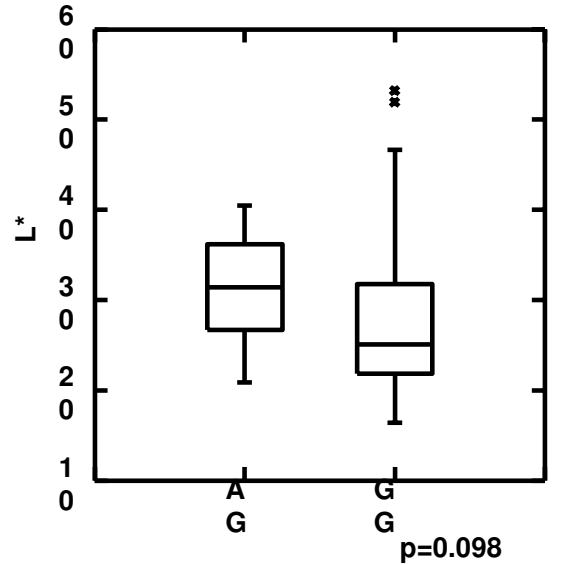

Figure 3

Box and whiskers plot of tristimulus colorimetry $L^{*}, \mathbf{a}^{*}$ and $\mathbf{b}^{*}$ values (hair colour) of Scottish individuals ( $\mathbf{N}=$ I 07) with the KITLG SNP rs I 492354. Significance and variance was calculated using ANOVA. usually have mild symptoms and mice mutated in the orthologous gene (Hps3) have the cocoa phenotype which produces a lighter coat colour and prolonged bleeding time but does not have a lysosomal disorder [28][29][30]. We suggest that variation within the human orthologues of the 17 mouse HPS-like genes merits further detailed analysis as candidates for contributing to hair colour variation.

\section{Conclusions}

We have found novel associations between SNPs in pigmentation genes previously shown to play a role in human hair and eye colour and colorimetrically assessed hair colour in a Scottish and a Danish population.

\section{Competing interests}

The authors declare that they have no competing interests.

\section{Authors' contributions}

All authors have read and approved the final manuscript. JM-F designed and performed experiments, analysed data and wrote the paper, nd TW designed and performed experiments, collected clinical samples and data and analysed data. NM designed experiments and analysed data, JLR designed experiments and analysed data and IJJ designed experiments, analysed data and wrote the paper.

\section{Acknowledgements}

The authors would like to take the opportunity to thank Veronique Vitart for her scientific comments. This work was funded by the Copenhagen University $\mathrm{PhD}$ program, the Institute of Forensic Medicine and the award of a MRC (UK) Clinical Research Training Fellowship to TW.

\section{References}

I. Harrison GA: Differences in human pigmentation: measurement, geographic variation and causes. Jounal of Investigative Dermatology 1973, 60:418-426.

2. Shekar SN, Duffy DL, Frudakis T, Montgomery GW, James MR, Sturm RA, Martin NG: Spectrophotometric methods for quantifying pigmentation in human hair-influence of MCIR genotype and environment. Photochemistry and Photobiology 2008, 84:719-726.

3. Eiberg $\mathrm{H}$, Mohr J: Assignment of genes coding for brown eye colour (BEY2) and brown hair colour (HCL3) on chromosome I5q. European Journal of Human Genetics 1996, 4:237-24I.

4. Shekar SN, Duffy DL, Frudakis T, Sturm RA, Zhao ZZ, Montgomery GW, Martin NG: Linkage and Association Analysis of Spectrophotometrically Quantified Hair Color in Australian Adolescents: the Effect of OCA2 and HERC2. Journal of Investigative Dermatology 2008, I 28:2807-28|4.

5. Sulem P, Gudbjartsson DF, Stacey SN, Helgason A, Rafnar T, Magnusson KP, Manolescu A, Karason A, Palsson A, Thorleifsson G, et al:: Genetic determinants of hair, eye and skin pigmentation in Europeans. Nature Genetics 2007, 39: | 1443-I452.

6. Eiberg H, Troelsen J, Nielsen M, Mikkelsen A, Mengel-From J, Kjaer $\mathrm{KW}$, Hansen L: Blue eye color in humans may be caused by a perfectly associated founder mutation in a regulatory element located within the HERC2 gene inhibiting OCA2 expression. Human Genetics 2008, I23:177-187.

7. Sturm RA, Duffy DL, Zhao ZZ, Leite FPN, Stark MS, Hayward NK, Martin NG, Montgomery GW: A single SNP in an evolutionary conserved region within intron 86 of the HERC2 gene determines human blue-brown eye color. American Journal of Human Genetics 2008, 82:424-43I.

8. Kayser M, Liu F, Cecile A, Janssens JW, Rivadeneira F, Lao $O$, van Duijn K, Vermeulen M, Arp P, Jhamai MM, et al.: Three genomewide association studies and a linkage analysis identify HERC2 as a human iris color gene. American Journal of Human Genetics 2008, 82:4II-423.

9. Valverde P, Healy E, Jackson I, Rees JL, Thody AJ: Variants of the Melanocyte-Stimulating Hormone-Receptor Gene Are Associated with Red Hair and Fair Skin in Humans. Nature Genetics 1995, I I:328-330.

10. Flanagan N, Healy E, Ray A, Philips S, Todd C, Jackson IJ, Birch-Machin MA, Rees JL: Pleiotropic effects of the melanocortin I recep- 
tor (MCIR) gene on human pigmentation. Human Molecular Genetics 2000, 9:253I-2537.

II. Wong TH, Rees JL: The relation between melanocortin I receptor $(M C I R)$ variation and the generation of phenotypic diversity in the cutaneous response to ultraviolet radiation. Peptides 2005, 26: | 965-1971.

12. Duffy DL, Box NF, Chen W, Palmer JS, Montgomery GW, James MR Hayward NK, Martin NG, Sturm RA: Interactive effects of MCIR and OCA2 on melanoma risk phenotypes. Human Molecular Genetics 2004, 13:447-46I.

13. Grimes EA, Noake PJ, Dixon L, Urquhart A: Sequence polymorphism in the human melanocortin I receptor gene as an indicator of the red hair phenotype. Forensic Science International 200I, I 22:124-129.

14. Mengel-From J, Borsting C, Sanchez JJ, Eiberg H, Morling N: Determination of cis/trans phase of variations in the MCIR gene with allele-specific PCR and single base extension. Electrophoresis 2008, 29:4780-4787.

15. Graf J, Hodgson R, van Daal A: Single nucleotide polymorphisms in the MATP gene are associated with normal human pigmentation variation. Human Mutation 2005, 25:278-284.

16. Han JL, Kraft P, Nan H, Guo Q, Chen C, Qureshi A, Hankinson SE, Hu FB, Duffy DL, Zhao ZZ, Martin NG, Montgomery GW, Hayward NK, Thomas G, Hoover RN, Chanock S, Hunter DJ: A genomewide association study identifies novel alleles associated with hair color and skin pigmentation. Plos Genetics 2008, 4(5): $\mathrm{el} 000074$.

17. Sulem P, Gudbjartsson DF, Stacey SN, Helgason A, Rafnar T, Jakobsdottir M, Steinberg S, Gudjonsson SA, Palsson A, Thorleifsson G, et al: Two newly identified genetic determinants of pigmentation in Europeans. Nature Genetics 2008, 40:835-837.

18. Steemers FJ, Gunderson KL: Illumina, Inc. Pharmacogenomics 2005 , 6:777-782.

19. Fan JB, Oliphant A, Shen R, Kermani BG, Garcia F, Gunderson KL, Hansen M, Steemers F, Butler SL, Deloukas P, et al.: Highly parallel SNP genotyping. Cold Spring Harb Symp Quant Biol 2003, 68:69-78.

20. Kanetsky PA, Rebbeck TR, Hummer AJ, Panossian S, Armstrong BK Kricker A, Marrett LD, Millikan RC, Gruber SB, Culver HA, et al.: Population-based study of natural variation in the melanocortin-I receptor gene and melanoma. Cancer Research 2006 66:9330-9337.

21. Purcell S, Neale B, Todd-Brown K, Thomas L, Ferreira MAR, Bender D, Maller J, Sklar P, de Bakker PIW, Daly MJ, et al.: PLINK: A tool set for whole-genome association and population-based linkage analyses. American Journal of Human Genetics 2007, 81:559-575.

22. Barrett JC, Fry B, Maller J, Daly MJ: Haploview: analysis and visualization of LD and haplotype maps. Bioinformatics 2005 21:263-265.

23. Vaughn $M$, van Oorschot R, Baindur-Hudson S: Hair color measurement and variation. American Journal of Physical Anthropology 2008, 137:91-96.

24. Steel KP, Davidson DR, Jackson IJ: TRP2/DCT, a new early melanoblast marker, shows that steel growth factor (c-kit ligand) is a survival factor. Development 1992, I I 5: I I I-I I I9.

25. Sturm RA: Molecular genetics of human pigmentation diversity. Human Molecular Genetics 2009, I8:R9-R I7.

26. Li W, Rusiniak ME, Chintala S, Gautam R, Novak EK, Swank RT: Murine Hermansky-Pudiak syndrome genes: regulators of lysosome-related organelles. Bioessays 2004, 26:616-628.

27. Wei ML: Hermansky-Pudlak syndrome: a disease of protein trafficking and organelle function. Pigment Cell Research 2006, 19:19-42.

28. Oh J, Ho LL, Ala-Mello S, Amato D, Armstrong L, Bellucci S, Carakushansky G, Ellis JP, Fong CT, Green JS, et al:: Mutation analysis of patients with Hermansky-Pudlak syndrome: A frameshift hot spot in the HPS gene and apparent locus heterogeneity. American Journal of Human Genetics 1998, 62:593-598.

29. Novak EK, Sweet HO, Prochazka M, Parentis M, Soble R, Reddington M, Cairo A, Swank RT: Cocoa - A New Mouse Model for Platelet Storage Pool Deficiency. British Journal of Haematology 1988, 69:37I-378.

30. Suzuki T, Li W, Zhang Q, Novak EK, Sviderskaya EV, Wilson A, Bennett DC, Roe BA, Swank RT, Spritz RA: The gene mutated in cocoa mice, carrying a defect of organelle biogenesis, is a homologue of the human Hermansky-Pudlak syndrome-3 gene. Genomics 200I, 78:30-37.
Publish with Biomed Central and every scientist can read your work free of charge

"BioMed Central will be the most significant development for disseminating the results of biomedical research in our lifetime. "

Sir Paul Nurse, Cancer Research UK

Your research papers will be:

- available free of charge to the entire biomedical community

- peer reviewed and published immediately upon acceptance

- cited in PubMed and archived on PubMed Central

- yours - you keep the copyright 